\title{
MULTIPLE RUPTURES OF CHOROID WITH RETENTION OF GOOD VISION
}

BY

\author{
HUMPHREY NEAME \\ LONDON
}

As it is commonly the case that rupture of the choroid is associated with damage to the macula and serious impairment of central vision, the following case seems worthy of report.

E. F., aged 19 years, suffered a blow in the left eye from the handle of a broom on April 26, 1940. His work is described as that of a " rivetter's boy," which involves looking at red-hot bolts in a furnace.

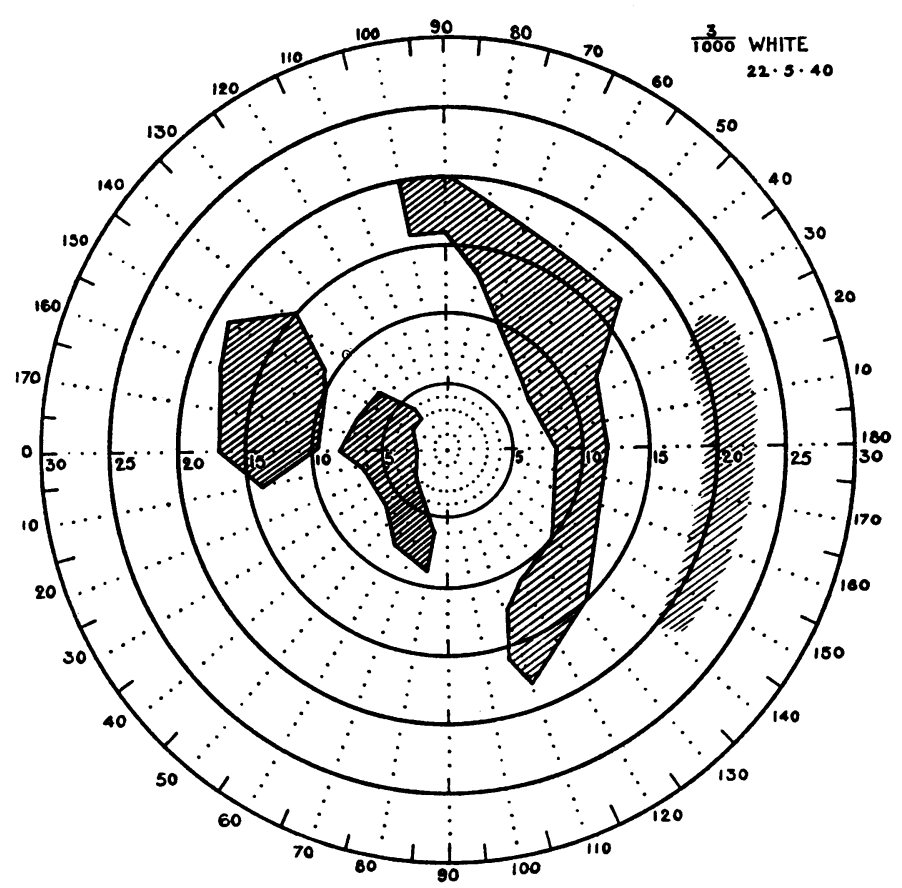

FIG. 2 .

Chart from Bjerrum's screen ( $\frac{3}{1000}$ white object). The left-hand scotoma represents the blind spot higher than normal presumably from head-tilting. To the right of that is a scotoma connected with the two ruptures between the disc and macula. The righthand hatched area without a boundary line was not well defined in the test with an object of $\frac{3}{100} \delta$ white but represents the long rupture to the temporal side in Fig. 1. 
On admission to Moorfields Eye Hospital the same day the vision of the right eye was $6 / 6$ and that of the left $6 / 60$. The eye was congested, the pupil oval and partly dilated and only reacting slightly to light. There was a small rupture of the iris sphincter in the superior nasal region. The corneal microscope revealed cells in abundance in the anterior chamber. Four more or less central choroidal tears were present on the temporal side of the disc, as in the figure. The fovea lay nearly mid-way between the second and third. There was some vitreous haemorrhage, no detachment of retina visible, some commotio retinae was evident in the inferior nasal region towards the periphery.

The congestion subsided fairly rapidly. The vitreous cleared completely, the macula showed delicate radiating folds as indicated in modification of the retinal light reflex.

On May 22, 1940, the vision of the left eye with +0.25 cyl., $90^{\circ}$, was $6 / 12$. The patient at this time had no discomfort in his eye and was ready to return to work.

The chart representing scotomata as taken with a $3 / 1000$ white object on May 22, 1940, on Bjerrum screen shows the blind spot somewhat above the normal position, no doubt owing to tilting of the head at the time of examination. The scotoma nearest to the blind spot extending between $2^{\circ}$ and $8^{\circ}$ presumably includes the area of the two nearest choroidal ruptures. The scotoma in the temporal field was not well defined with an object of 3 millimetres diameter and is indicated approximately.

\section{A CASE OF EXFOLIATION OF THE LENS CAPSULE WITH THE PATHOLOGICAL REPORT}

BY

\section{Alexander Garrow and I. C. Michaelson \\ GLASGOW}

\section{Clinical Note. A.G.}

THE patient, a robust and healthy looking man, age 69 years, was seen for the first time on March 15, 1938, complaining of defective vision of the right eye of one year's duration. This was found to be due to detachment of the retina and an intra-ocular tumour was diagnosed as the cause of it. The eye was removed on April 6 and the growth was found to be a melanotic sarcoma of the choroid.

For the better examination of the fundus a mydriatic was used in the right eye. The slit-lamp revealed well marked exfoliation of the lens capsule. There was a central film with curled and 